Check for updates

Cite this: RSC Adv., 2017, 7, 36138

\title{
Carbon nanosphere-iron oxide nanocomposites as high-capacity adsorbents for arsenic removal $\dagger$
}

\begin{abstract}
Hui Su, ${ }^{a}$ Zhibin Ye, iD ${ }^{* a b}$ Nuri Hmidic and Ramesh Subramanian ${ }^{a}$
In the design of iron oxide-derived composite adsorbents for arsenic removal, the matrix selected for the encapsulation of iron oxide active material is critical to their arsenic adsorption performance. The ideal matrix should have a high surface area, high pore volume, and large pores that can accommodate the iron oxide nanoparticles while without causing the undesired pore filling or blockage. In this paper, we report the use of carbon nanospheres (size of ca. $28 \mathrm{~nm}$ ) featuring high surface area, high pore volume, and hierarchical large mesopore/macropore structures resulting from nanosphere packing/aggregation as the matrix for the design of iron oxide composites. Iron oxide has been encapsulated into the carbon nanospheres with different contents (7-60 wt\%). The composites have been systematically characterized for their structural, morphological, and textural properties, and investigated for their performance for arsenic adsorption. An optimum iron oxide content of $13 \mathrm{wt} \%$ has been established with high adsorption capacities of 416 and $201 \mathrm{mg} \mathrm{g}^{-1}$ achieved for As(III) and As(v), respectively, which are highest (for As(III)) or among the highest (for As(v)) reported thus far for iron oxide-based adsorbents. These are in contrast to the typically low adsorption capacities found with iron oxide composites involving other carbonbased matrices, such as activated carbon, carbon nanotubes, and mesoporous carbons. The results confirm the high potential of this class of composite adsorbents for arsenic removal. Meanwhile, the structure-performance relationship demonstrated herein is also of value to the further design of high-

performance arsenic adsorbents.
\end{abstract}

Received 3rd June 2017

Accepted 13th July 2017

DOI: $10.1039 / \mathrm{c} 7 \mathrm{ra06187k}$

rsc.li/rsc-advances

\section{Introduction}

Arsenic is a persistent, bio-accumulative, toxic element, which is widely distributed in the Earth's crust with an average terrestrial content of about $5 \mathrm{~g}$ per ton. ${ }^{1}$ Arsenic contamination of natural water sources due to mineral leaching and/or anthropogenic activities has been recorded by World Health Organization as a first priority issue. ${ }^{1-3}$ Various techniques have been developed to remove arsenic from both natural and industrial water sources, including coagulation, adsorption, ion exchange, membrane filtration, biological remediation, etc. The advantages and disadvantages of each technique have been well presented in the existing literature..$^{3-6}$ In particular, adsorption is most economical and efficient over other techniques, especially in the low arsenic concentration range. A broad spectrum of adsorbents has been extensively studied and developed for arsenic removal.,

${ }^{a}$ Bharti School of Engineering, Laurentian University, Sudbury, Ontario P3E 2C6, Canada.E-mail: zye@laurentian.ca; zhibin.ye@concordia.ca

${ }^{b}$ Department of Chemical and Materials Engineering, Concordia University, Montreal, Quebec H3G 1M8, Canada

${ }^{c}$ Goldcorp Incorporated, Red Lake Gold Mines, 15 Mine Road, Box 2000, Balmertown, Ontario POV 1C0, Canada

$\dagger$ Electronic supplementary information (ESI) available. See DOI: 10.1039/c7ra06187k
Iron oxide-derived adsorbents have received, in particular, enormous interest for arsenic removal due to their superior performance for arsenic adsorption while with low cost. ${ }^{7}$ Iron oxides in various forms have been studied, such as amorphous iron oxide, ${ }^{8,9}$ crystalline iron oxides, ${ }^{10-14}$ and various iron oxide nanostructures. ${ }^{15-22}$ Among the various forms of iron oxides, amorphous iron oxides show the highest adsorption capacity (as high as 260 and $200 \mathrm{mg} \mathrm{g}^{-1}$ for As(III) and As(v), respectively) due to its highest specific surface area, ${ }^{\mathbf{1 0}}$ but with the difficulty (as fine powders) for separation and its tendency to form lowsurface-area crystalline iron oxides during preparation. ${ }^{4}$ Crystalline iron oxides and iron oxide nanostructures generally show lowered adsorption capacity due to their relatively low surface area. ${ }^{12-22}$

To facilitate more convenient adsorbent separation, iron oxide-derived composite adsorbents with iron oxides loaded onto various matrices have also been extensively developed for arsenic adsorption. ${ }^{3,4}$ In this aspect, a careful selection of the appropriate matrices and the uniform dispersion of iron oxide are key to the performance of the resulting composite adsorbents. The desired matrices should have open, 3-dimensional, interconnected pore structures with accessible, high surface area and pore volume. Meanwhile, the pore size of the matrices should be significantly larger than that of the loaded iron oxide nanoparticles, particularly at high iron oxide content, so as to 
avoid or minimize pore blockages, which would otherwise affect the mass diffusion and consequently the adsorption performance. Typical matrices have included abundant ones, such as naturally occurring minerals, ${ }^{23}$ activated carbons, ${ }^{24}$ graphene oxide (GO), ${ }^{25-36}$ and cellulose,$^{37}$ as well as some speciallysynthesized ones, such as mesoporous carbons, ${ }^{\mathbf{3 8 , 3 9}}$ carbon nanotubes, ${ }^{\mathbf{4 0}}$ macroporous silica, ${ }^{\mathbf{4 1}}$ etc. The majority of composite adsorbents reported to date show limited arsenic adsorption capacities, with significant room for improvements. One exception is the iron oxide-macroporous silica foam composite adsorbent reported by $\mathrm{Yu}$ et al., ${ }^{\mathbf{4 1}}$ which shows remarkably high adsorption capacity [320 and $248 \mathrm{mg} \mathrm{g}^{-1}$ for As(III) and As(v), respectively]. Therein, the encapsulation of iron oxide at high contents (up to $34.8 \mathrm{wt} \%$ ) does not block the open pore structures of the macroporous silica foam substrate having large macropores.

In this article, carbon nanospheres (CNS) having unique hierarchical large meso-/macropore structures ${ }^{\mathbf{4 2}}$ are chosen for the first time as the porous matrix to fabricate iron oxide nanocomposite adsorbents of high arsenic adsorption capacity. Iron oxide has been loaded onto the CNS matrix at different content (7-60 wt\%). The resulting composites have been systematically characterized with various techniques for their compositional, structural, and textural properties. Their performance for arsenic adsorption has been evaluated. High adsorption capacities of 416 and $201 \mathrm{mg} \mathrm{g}^{-1}$ for As(III) and As(v), respectively, have been achieved, which are even better than or comparable to the best results demonstrated thus far in the literature for iron oxide-derived composite adsorbents.

\section{Experimental}

\section{Materials}

1,3-Diethynylbenzene (DEB, 97\%, Aldrich), sodium dodecyl sulphate (SDS, $\geq 98.5 \%$, Aldrich), palladium acetate (98\%, Strem Chemicals), $\alpha, \alpha^{\prime}$-bis(di-tert-butylphosphino)-o-xylene (97\%, Strem Chemicals), methanol (ACS reagent, Fisher Scientific), methanesulfonic acid (99.5\%, Aldrich), dichloromethane (HPLC grade, Aldrich), ammonium persulfate (98\%, Aldrich), sulfuric acid (96.9 wt\%, Fisher Scientific), iron(III) nitrate nonahydrate ( $\geq 98 \%$, Aldrich), ethanol (ACS reagent, Fisher Scientific), were used as received without any additional purification. Deionized water was purified by a Barnstead/Synbron Nanopure II purification system.

Sodium (meta)arsenite $\left(\mathrm{NaAsO}_{2}, \geq 90 \%\right.$, Aldrich) and sodium arsenate dibasic heptahydrate $\left(\mathrm{Na}_{2} \mathrm{HAsO}_{4} \cdot 7 \mathrm{H}_{2} \mathrm{O}\right.$, $\geq 98 \%$, Aldrich) were used as the source of $\operatorname{As}(\mathrm{III})$ and $\operatorname{As}(\mathrm{v})$, respectively. Fresh ammonium persulfate (APS) solution at $1.0 \mathrm{M}$ was prepared in $2 \mathrm{M} \mathrm{H}_{2} \mathrm{SO}_{4}$. $\mathrm{Fe}\left(\mathrm{NO}_{3}\right)_{3}$ solution at $20 \mathrm{wt} \%$ was freshly prepared in ethanol. Standard stock solutions of $\mathrm{As}(\mathrm{III})$ and $\mathrm{As}(\mathrm{v})$ were prepared in deionized water at an arsenic concentration of $2000 \mathrm{mg} \mathrm{L}^{-1}$. The standard solutions with other different concentrations were prepared by diluting the standard stock solutions. The $\mathrm{pH}$ of the standard solutions was adjusted to desired values by adding an appropriate amount of $\mathrm{HNO}_{3}$ or $\mathrm{NaOH}$ solution (both at $1 \mathrm{M}$ ).

\section{Synthesis of carbon nanospheres (CNS) and $\mathrm{CO}_{2}$-activated carbon nanospheres (A-CNS)}

CNS was synthesized by a catalytic emulsion polymerization technique developed by our group. ${ }^{42}$ This technique involves the first synthesis of highly cross-linked poly(1,3diethynylbenzene) nanospheres (average size of ca. $24 \mathrm{~nm}$ ) by catalytic emulsion polymerization of $\mathrm{DEB}$, followed by hydrothermal treatment and subsequent carbonization. For the emulsion polymerization, sodium dodecyl sulfate (SDS) (1.6 g) was dissolved in deionized water $(31.2 \mathrm{~g})$ in a round-bottom Schlenk flask, followed by the addition of DEB (3.72 g; 29.5 $\mathrm{mmol}$ ). The mixture was sonicated for $15 \mathrm{~min}$ and was then stirred for $5 \mathrm{~h}$ at $60{ }^{\circ} \mathrm{C}$. In the meantime, palladium acetate (6.62 mg; $0.03 \mathrm{mmol}$ ) and $\alpha, \alpha^{\prime}$-bis(di-t-butylphosphino)-o-xylene (34.9 mg; $0.09 \mathrm{mmol}$ ) were dissolved in a mixture solvent containing $0.54 \mathrm{~mL}$ of dichloromethane and $0.06 \mathrm{~mL}$ of methanol to prepare a catalyst solution. Then the catalyst solution was injected into the flask, followed by the addition of five drops of methanesulfonic acid, to start the miniemulsion polymerization. The polymerization lasted overnight in $\mathrm{N}_{2}$ atmosphere under stirring at $450 \mathrm{rpm}$ at $60{ }^{\circ} \mathrm{C}$, rendering a dark brown emulsion dispersion of polymer nanospheres. A hydrothermal treatment of the resulting polymer nanospheres was subsequently undertaken. The emulsion was diluted and was hydrothermally treated in an autoclave at $220{ }^{\circ} \mathrm{C}$ overnight. The resulting hydrothermally treated polymer precipitates were collected by filtration, washed with a large amount of water, and dried under vacuum at $60{ }^{\circ} \mathrm{C}$ for $48 \mathrm{~h}$, rendering the polymer nanospheres $(2.77 \mathrm{~g})$. Pyrolysis of the polymer nanospheres in a tube furnace at $800{ }^{\circ} \mathrm{C}$ for $1 \mathrm{~h}$ in a nitrogen atmosphere (preceded with heating from room temperature to $800{ }^{\circ} \mathrm{C}$ at a heating rate of $10{ }^{\circ} \mathrm{C} \mathrm{min}^{-1}$ ) rendered CNS (1.65 g).

A-CNS was prepared by $\mathrm{CO}_{2}$ activation of CNS at $900^{\circ} \mathrm{C}$ for $3 \mathrm{~h}$. In a tube furnace, CNS (1.65 g) was heated to $900{ }^{\circ} \mathrm{C}$ at a rate of $10{ }^{\circ} \mathrm{C} \min ^{-1}$ in a flowing $\mathrm{N}_{2}$ atmosphere. After reaching $900{ }^{\circ} \mathrm{C}$, the atmosphere was changed from $\mathrm{CO}_{2}$ within $5 \mathrm{~min}$ and the temperature was maintained for $3 \mathrm{~h}$. When the activation was finished, the atmosphere was switched back to $\mathrm{N}_{2}$ within $5 \mathrm{~min}$, followed by natural cooling of the sample down to room temperature in the $\mathrm{N}_{2}$ atmosphere, rendering A-CNS (0.8 g).

\section{Synthesis of iron oxide-CNS composites $\left(\mathrm{FeO}_{\boldsymbol{x}}-\mathrm{CNSs}\right)$}

Iron oxide-CNS composites were synthesized by modifying a literature method reported for the preparation of iron oxidemesoporous carbon nanocomposites. ${ }^{38}$ Surface oxidation of ACNS with APS was first undertaken to render S-CNS with improved surface polarity for the loading of iron oxide. A-CNS (240 mg) was dispersed and stirred in $20 \mathrm{~mL}$ of $1.0 \mathrm{M}$ acidic APS solution (in $2 \mathrm{M} \mathrm{H}_{2} \mathrm{SO}_{4}$ ) at $70{ }^{\circ} \mathrm{C}$ for $12 \mathrm{~h}$. The solids were then filtered, washed with copious amounts of water and then methanol, and dried under vacuum at $60{ }^{\circ} \mathrm{C}$ overnight, rendering S-CNS (200 mg).

The following is the procedure used for the synthesis of the representative iron oxide-CNS nanocomposite having an iron oxide content of $13 \mathrm{wt} \%$ (i.e., $\left.\mathrm{FeO}_{x}-\mathrm{CNS}-13\right)$. S-CNS $(200 \mathrm{mg}$ ) was dispersed in absolute ethanol (1.4 g), followed by the addition of 
a $20 \mathrm{wt} \%$ ethanolic solution of $\mathrm{Fe}\left(\mathrm{NO}_{3}\right)_{3}(152 \mathrm{mg}, 374 \mathrm{mmol})$. After sufficient and subsequent solvent evaporation, the resulting powder was transferred into a small plastic ampoule. The ampoule was subsequently placed in a Teflon bottle containing an ammonia solution $(\sim 10 \mathrm{~mL}$ at $\sim 14 \mathrm{wt} \%)$, but without direct contact of the powder with the ammonia solution. After sealing, the bottle was heated in an oven at $60{ }^{\circ} \mathrm{C}$ for $3 \mathrm{~h}$ to hydrolyze the metal precursor in situ. After cooling, the product was filtered and washed with small amounts of water and methanol. After drying at $60{ }^{\circ} \mathrm{C}$ under vacuum overnight, the solid product was pyrolyzed at $300{ }^{\circ} \mathrm{C}$ in a $\mathrm{N}_{2}$ atmosphere for $1 \mathrm{~h}$ to obtain $\mathrm{FeO}_{x}-\mathrm{CNS}-13$ (0.2 g).

Other nanocomposites $\left(\mathrm{FeO}_{x}-\mathrm{CNS}-7, \mathrm{FeO}_{x}-\mathrm{CNS}-28\right.$, and $\left.\mathrm{FeO}_{x}-\mathrm{CNS}-60\right)$ having different contents of iron oxide $(7,28$, and $60 \mathrm{wt} \%$, respectively) were similarly prepared with the feed amounts of S-CNS and iron nitrate at different mass ratios (50 $\mathrm{mg} / 19 \mathrm{mg}, 100 \mathrm{mg} / 197 \mathrm{mg}$, and $50 \mathrm{mg} / 380 \mathrm{mg}$, respectively).

\section{Characterization and measurements}

Thermogravimetric analysis (TGA) of the various composites was carried out on a Q50 TGA from TA Instruments. Measurements were performed in an air atmosphere with a continuous airflow of $60 \mathrm{~mL} \mathrm{~min}{ }^{-1}$ through the sample furnace and a continuous $\mathrm{N}_{2}$ flow of $40 \mathrm{~mL} \mathrm{~min}^{-1}$ through the balance compartment. In a typical measurement, the sample $(10 \mathrm{mg})$ was heated to $100{ }^{\circ} \mathrm{C}$ at a rate of $10{ }^{\circ} \mathrm{C} \mathrm{min}{ }^{-1}$, held at $100{ }^{\circ} \mathrm{C}$ for $10 \mathrm{~min}$, and then heated to $800{ }^{\circ} \mathrm{C}$ at a rate of $10^{\circ} \mathrm{C} \mathrm{min}{ }^{-1} . \mathrm{N}_{2}$ sorption analysis was carried out with a Micromeritics ASAP 2020 physiosorption analyzer at $77 \mathrm{~K}$ to determine their Braunauer-Emmett-Teller (BET) specific surface area, pore volume, and pore size distribution. Before the sorption measurements, the samples were degassed under vacuum at $180{ }^{\circ} \mathrm{C}$ for at least $12 \mathrm{~h}$. X-ray photoelectron spectroscopy (XPS) measurements of the samples were carried out on a Thermo Scientific Theta Probe XPS spectrometer. A monochromatic Al K $\alpha$ X-ray source was used, with a spot area of $400 \mu \mathrm{m}$. The samples were run in a standard mode, i.e., all angles collected $\left(60^{\circ}\right.$ angular acceptance) for the survey spectra, and for the region spectra. Wideangle X-ray diffraction (XRD) patterns were recorded on an X'Pert Pro diffractometer with Cu radiation (wavelength $1.54 \AA$ ) at room temperature. Transmission electron microscopy (TEM) images were taken on a JEOL $2010 \mathrm{~F}$ field emission electron microscope operated at $200 \mathrm{keV}$, equipped with energydispersive spectroscopy (EDS). The TEM samples were prepared by depositing a few drops of a dilute dispersion of the samples in methanol on holey grids, followed by drying. Dynamic light scattering (DLS) and zeta potential measurements of the dilute dispersions $\left(0.1 \mathrm{mg} \mathrm{mL}^{-1}\right)$ of the various samples were performed on a Brookhaven NanoBrook Omni Instrument at $25{ }^{\circ} \mathrm{C}$. Fourier-transformed infrared (FTIR) spectra were obtained on a Thermo Scientific Nicolet 6700 Analytical FTIR spectrometer. The samples were prepared as pellets using spectroscopic-grade $\mathrm{KBr}$. The arsenic concentration of the various aqueous solutions in the adsorption study was measured with an Analytik Jena 810 ICP-MS system with a detection limit of $50 \mu \mathrm{g} \mathrm{L}^{-1}$.

\section{Arsenic adsorption}

Batch adsorption of arsenic with all adsorbents (A-CNS, S-CNS, or $\mathrm{FeO}_{x}$-CNS composites) was all undertaken with an adsorbent loading of $1.0 \mathrm{mg} \mathrm{mL}^{-1}$ at $23{ }^{\circ} \mathrm{C}$. Typically, the adsorbent $(1 \mathrm{mg})$ was dispersed in various $\mathrm{As}(\mathrm{III})$ or $\mathrm{As}(\mathrm{v})$ solutions $(1 \mathrm{~mL})$ at different known concentrations (50-2000 $\mathrm{mg} \mathrm{L}^{-1}$ ), followed by magnetic stirring (300 rpm) for $24 \mathrm{~h}$ to achieve equilibrium. Afterwards, the dispersion was filtered with $0.2 \mu \mathrm{m}$ syringe filter and the filtrate was measured with ICP-MS for equilibrium arsenic concentration and for the calculation of the amount of adsorbed arsenic to construct adsorption isotherms. The adsorption isotherms were fitted with Freundlich model (eqn (1)).

$$
q_{\mathrm{e}}=k\left(C_{\mathrm{e}}\right)^{1 / n}
$$

where $q_{\mathrm{e}}$ is the equilibrium adsorption uptake $\left(\mathrm{mg} \mathrm{g}^{-1}\right), C_{\mathrm{e}}$ is the equilibrium concentration (in $\mathrm{mg} \mathrm{L}^{-1}$ ), $k$ is the Freundlich constant, and $n$ is the index that stands for adsorption strength.

To obtain the adsorption kinetic curves, $\mathrm{FeO}_{x}-\mathrm{CNS}-13(1 \mathrm{mg})$ was dispersed in a series of As(III) and As(v) solutions with the same volume $(1 \mathrm{~mL})$ and initial concentrations $\left(950 \mathrm{mg} \mathrm{L}^{-1}\right.$ for As(III) and $800 \mathrm{mg} \mathrm{L}^{-1}$ for As(v)). Each dispersion was stirred for a prescribed period of time (ranging from $15 \mathrm{~min}$ to $24 \mathrm{~h}$ ) and was quickly filtered for measurement of the corresponding equilibrium concentration of $\mathrm{As}(\mathrm{III})$ and $\mathrm{As}(\mathrm{v})$, thus giving rise to the time-dependent adsorption uptake. The adsorption kinetics was fitted with the pseudo-second-order kinetic model (eqn (2) or (3)) based on which the initial adsorption rate was obtained (eqn (4)).

$$
\begin{gathered}
\mathrm{d} q_{t} / \mathrm{d} t=k_{2}\left(q_{\mathrm{e}}-q_{t}\right)^{2} \\
t / q_{t}=1 /\left(k_{2} q_{\mathrm{e}}{ }^{2}\right)+t / q_{\mathrm{e}} \\
V_{0}=k_{2} q_{\mathrm{e}}{ }^{2}
\end{gathered}
$$

where $q_{t}$ is the adsorption uptake $\left(\mathrm{mg} \mathrm{g}^{-1}\right)$ after a time of $t$ ( $\mathrm{min}), k_{2}$ is the rate constant $\left(\mathrm{g} \mathrm{mg}^{-1} \mathrm{~min}^{-1}\right)$, and $V_{0}$ is the initial adsorption rate $\left(\mathrm{mg} \mathrm{g}^{-1} \mathrm{~min}^{-1}\right)$.

\section{Results and discussion}

\section{Synthesis and characterization of carbon nanosphere matrix}

The carbon nanosphere matrix (S-CNS), employed herein for the construction of the composite adsorbents, was synthesized by $\mathrm{CO}_{2}$-activation of carbon nanospheres (CNS) obtained by a unique catalytic emulsion polymerization technique ${ }^{42}$ followed by surface oxidization. Scheme 1 summarizes the synthesis. The catalytic emulsion polymerization of a crosslinkable dialkyne monomer, DEB, rendered poly(DEB) polymer nanospheres of uniform sizes (average size of $27 \mathrm{~nm}$ with polydispersity index of 0.19 as per DLS characterization; see Fig. S1 in ESI $\dagger$ ). Therein, each polymer nanosphere was constructed uniquely with highly cross-linked poly(DEB) networks. Carbonization of the polymer nanospheres following hydrothermal treatment rendered $\mathrm{CNS}^{42}$ Having relatively low 


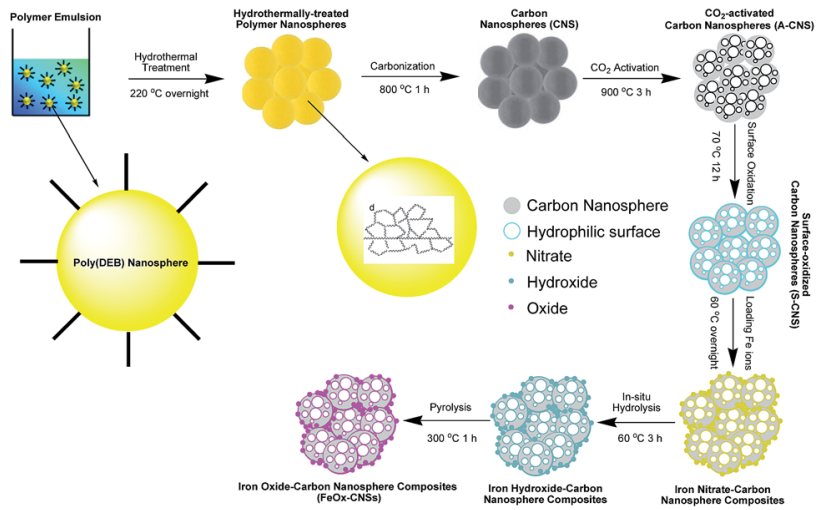

Scheme 1 Schematic synthesis of carbon nanosphere matrix and the $\mathrm{FeO}_{x}-\mathrm{CNS}$ nancomposites.

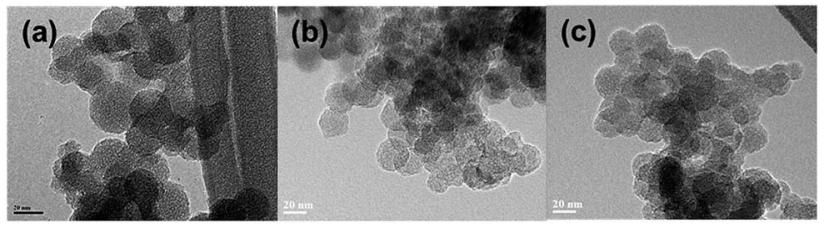

Fig. 1 TEM of CNS (a), A-CNS (b), and S-CNS (c).

specific surface area $\left(524 \mathrm{~m}^{2} \mathrm{~g}^{-1}\right)$ and pore volume $\left(0.84 \mathrm{~cm}^{3}\right.$ $\mathrm{g}^{-1}$ ) as shown below, CNS, directly, was unsuitable as the matrix for iron oxide. $\mathrm{CO}_{2}$ activation was thus employed to yield A-CNS with dramatically enhanced surface area and pore volume. Therein, the enhanced porosity is generated by the gasification reaction of the carbon structure with $\mathrm{CO}_{2}$, rendering $\mathrm{CO}^{43}$ Consisting predominantly of carbon, the surface of A-CNS was highly hydrophobic and incompatible with polar iron oxide. Wet chemical surface oxidation ${ }^{44}$ of A-CNS was further taken to render S-CNS with improved surface polarity in order for uniform encapsulation of iron oxide.
Fig. 1 shows TEM images of CNS, A-CNS, and S-CNS. CNS is comprised of aggregates of well-defined carbon nanospheres with average size of $24 \mathrm{~nm}$ (Fig. 1(a)). Following the $\mathrm{CO}_{2}$ activation, the nanosphere morphology is still well retained in ACNS (Fig. 1(b)). The average nanosphere size in A-CNS is $c a$. $28 \mathrm{~nm}$, which is slightly bigger than that in CNS, indicating the slight expansion of the carbon nanospheres due to mesopore/ micropore generation within the nanospheres upon $\mathrm{CO}_{2}$ activation. Surface oxidation leads to slight structural collapse in SCNS with fusion of some nanospheres observed; but the nanosphere morphology is still clearly retained (Fig. 1(c)).

$\mathrm{N}_{2}$ sorption analysis at $77 \mathrm{~K}$ was undertaken on the three carbon nanosphere samples to reveal their textural properties. Fig. 2(a) shows their $\mathrm{N}_{2}$ sorption curves, with the results summarized in Table 1. All three samples show typical type IV adsorption isotherm, ${ }^{45}$ with a slight uptake at low relative pressure $\left(P / P_{0}<0.05\right)$, and a sharp uptake at high relative pressure $\left(P / P_{0}>0.90\right.$ for CNS and A-CNS; $P / P_{0}>0.7$ for S-CNS $)$, indicating that all samples contain predominantly mesopores/ macropores. All samples have distinct type H3 hysteresis loops, ${ }^{45}$ which is characteristic of slit-shaped pores. Relative to CNS, A-CNS has dramatically enhanced surface area (2271 vs. $\left.524 \mathrm{~m}^{2} \mathrm{~g}^{-1}\right)$ and pore volume (5.18vs. $0.84 \mathrm{~cm}^{3} \mathrm{~g}^{-1}$ ) with the generation of a large quantity of new mesopores/macropores upon $\mathrm{CO}_{2}$ activation. However, upon further surface oxidation, the surface area and pore volume of S-CNS are reduced to $1073 \mathrm{~m}^{2} \mathrm{~g}^{-1}$ and $1.17 \mathrm{~cm}^{3} \mathrm{~g}^{-1}$, respectively, due to the slight unavoidable structural collapse. This is also accompanied with the reduction of the average meso-/macropore size from $41 \mathrm{~nm}$ for A-CNS to $20 \mathrm{~nm}$ for S-CNS. Despite this, S-CNS is suitable for the encapsulation of iron oxide given its high surface area/pore volume and large meso-/macropores.

All the three carbon nanosphere samples should have the characteristic hierarchical pore structures with the presence of both inter-sphere mesopores/macropores resulting from nanosphere aggregation/packing and intra-sphere micropores/ mesopores. They are predominantly mesoporous/
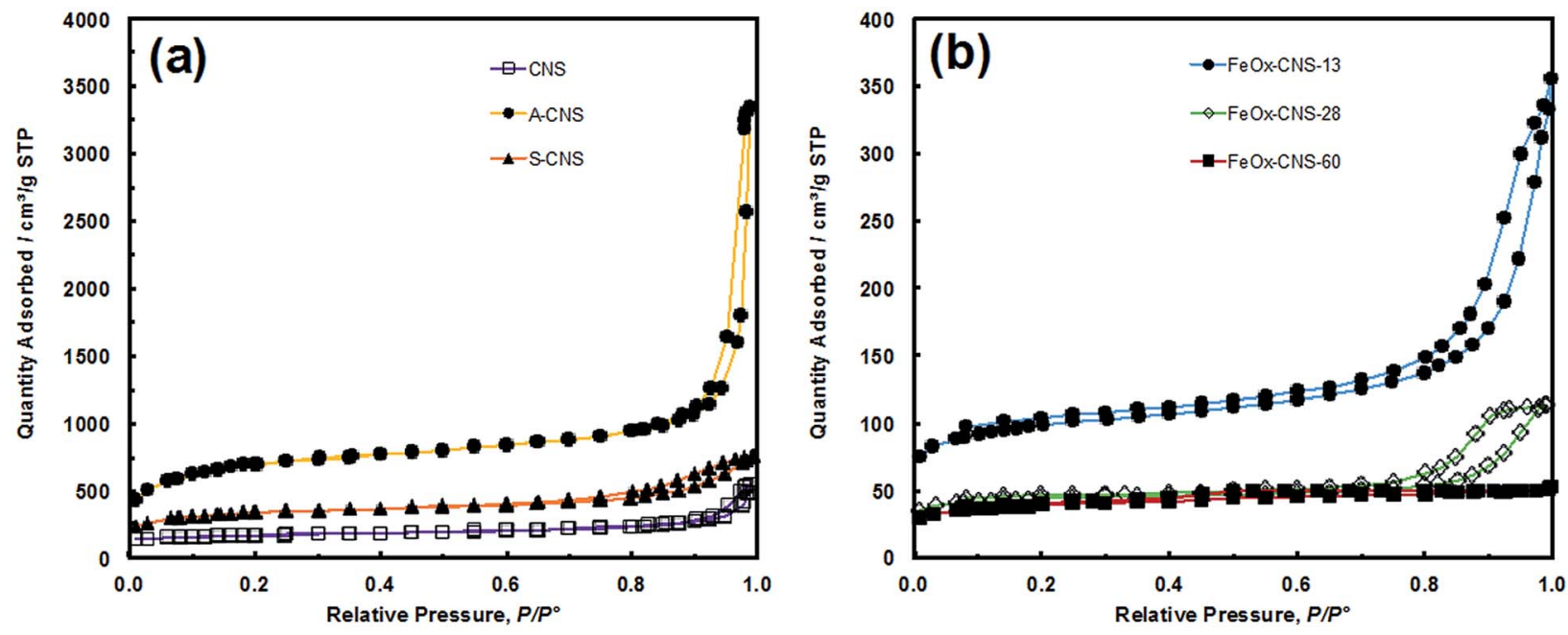

Fig. 2 (a) $\mathrm{N}_{2}$ sorption isotherm of CNS, A-CNS and S-CNS, (b) $\mathrm{N}_{2}$ sorption isotherm of $\mathrm{FeO}_{x}-\mathrm{CNS}^{-13}, \mathrm{FeO}_{x}-\mathrm{CNS}^{-28}$ and FeO $-\mathrm{CNS}-60$. 
Table 1 Results from $\mathrm{N}_{2}$ sorption characterization

\begin{tabular}{|c|c|c|c|c|c|c|c|c|c|}
\hline \multirow[b]{2}{*}{ Samples } & \multicolumn{4}{|c|}{ Surface area ${ }^{a}\left(\mathrm{~m}^{2} \mathrm{~g}^{-1}\right)$} & \multicolumn{4}{|c|}{ Pore volume ${ }^{b}\left(\mathrm{~cm}^{3} \mathrm{~g}^{-1}\right)$} & \multirow[b]{2}{*}{$D_{\text {meso/macro }}{ }^{c}(\mathrm{~nm})$} \\
\hline & $S_{\mathrm{BET}}$ & $S_{\text {micro }}$ & $\% S_{\text {micro }}$ & $S_{\text {meso/macro }}$ & $V_{\text {total }}$ & $V_{\text {micro }}$ & $\% V_{\text {micro }}$ & $V_{\text {meso/macro }}$ & \\
\hline CNS & 524 & 292 & $56 \%$ & 232 & 0.84 & 0.15 & $18 \%$ & 0.69 & 32 \\
\hline A-CNS & 2271 & 749 & $33 \%$ & 1522 & 5.18 & 0.41 & $8 \%$ & 4.77 & 41 \\
\hline S-CNS & 1073 & 458 & $43 \%$ & 615 & 1.17 & 0.25 & $21 \%$ & 0.92 & 20 \\
\hline $\mathrm{FeO}_{x}-\mathrm{CNS}-13$ & 311 & 168 & $54 \%$ & 143 & 0.55 & 0.09 & $16 \%$ & 0.46 & 24 \\
\hline $\mathrm{FeO}_{x}-\mathrm{CNS}-28$ & 135 & 88 & $65 \%$ & 47 & 0.22 & 0.05 & $23 \%$ & 0.17 & 20 \\
\hline $\mathrm{FeO}_{x}-\mathrm{CNS}-60$ & 123 & 60 & $49 \%$ & 63 & 0.08 & 0.03 & $38 \%$ & 0.05 & \\
\hline
\end{tabular}

${ }^{a}$ BET surface area $\left(S_{\mathrm{BET}}\right)$, surface area of micropores $\left(S_{\text {micro }}\right)$ and mesopores/macropores $\left(S_{\text {meso/macro }}\right)$ determined with $t$-plot method; \% $S_{\text {micro }}$ denotes the percentage of surface area of micropores. ${ }^{b}$ Total pore volume $\left(V_{\text {total }}\right)$, micropore volume $\left(V_{\text {micro }}\right)$ and mesopore/macropore volume $\left(V_{\text {meso/macro }}\right)$ determined with $t$-plot method; \% $V_{\text {micro }}$ denotes the percentage of micropore volume. ${ }^{c}$ Average mesopore/macropore size $\left(D_{\text {meso/macro }}\right)$ determined from the $\mathrm{N}_{2}$ desorption data with NLDFT model.

macroporous, with micropores contributing to only $8-21 \%$ of total pore volume (see Table 1). Fig. S2(a) in ESI $\dagger$ compares their mesopore/macropore size distribution curves. The 3-dimensional interconnected hierarchical mesopore/macropore structures of S-CNS, along with its high surface area and pore volume, is beneficial for rendering iron oxide composites with uniform encapsulation of iron oxide and in consequence high arsenic adsorption capacity.

XPS characterization (see Fig. S3 and S4 in ESI $\dagger$ ) shows that S-CNS has a high content (22.8 atom\%) of $\mathrm{O}$, which is much higher than those (4.4 and 7.7 atom\%, respectively) in CNS and A-CNS. Confirming the efficiency of surface oxidization, the high O content of S-CNS is beneficial for the subsequent even, uniform encapsulation of iron oxide. Fig. 3 compares their FTIR spectra. Both CNS and A-CNS show nearly featureless spectra, with only weak and broad bands in the frequency region of $1700-1000 \mathrm{~cm}^{-1}$ having two maxima at around $1570 \mathrm{~cm}^{-1}$ and $1149 \mathrm{~cm}^{-1}$. The broad bands can be assigned to the stretching vibrations of $\mathrm{C}-\mathrm{C}$ and $\mathrm{C}-\mathrm{H}$ bonds in aromatic carbon rings, respectively. ${ }^{46}$ New intense bands indicative of significant oxidation of the carbon surface are observed in the spectrum of

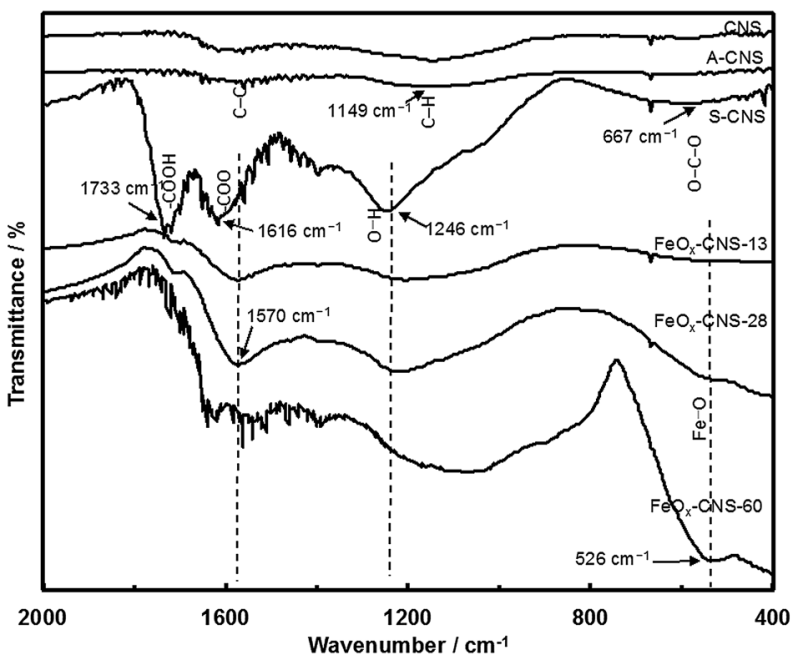

Fig. 3 FTIR spectra of CNS, A-CNS, S-CNS, $\mathrm{FeO}_{x}-\mathrm{CNS}-13, \mathrm{FeO}_{x}-$ CNS-28, and $\mathrm{FeO}_{x}-\mathrm{CNS}-60$.
S-CNS, which is in agreement with XPS results. The bands at 1733 and $1616 \mathrm{~cm}^{-1}$ can be assigned to asymmetric stretching vibrations of the newly formed - $\mathrm{COOH}$ carboxyl and - $\mathrm{COO}-$ carbonyl and/or $-\mathrm{C}=\mathrm{O}$ ketone units. ${ }^{44,47,48}$ The band at 1246 $\mathrm{cm}^{-1}$ can be attributed to asymmetric stretch of $-\mathrm{C}-\mathrm{C}-\mathrm{C}$ bridges in ketonic groups and/or to deformation vibrations of $\mathrm{O}-\mathrm{H}$ in the carboxylic acid groups. In addition, the weak band at 667 $\mathrm{cm}^{-1}$ can be assigned to bending $\mathrm{O}-\mathrm{C}-\mathrm{O}$ vibrations of carboxyl units. $^{41}$

\section{Synthesis and characterization of $\mathrm{FeO}_{x}-\mathrm{CNS}$ nanocomposites}

$\mathrm{FeO}_{x}-\mathrm{CNS}$ nanocomposites were synthesized by loading iron nitrate precursors $\left(\mathrm{Fe}\left(\mathrm{NO}_{3}\right)_{3} \cdot 9 \mathrm{H}_{2} \mathrm{O}\right)$ into the pore structures of S-CNS, followed by an in situ hydrolysis under ammonia atmosphere for the conversion of the iron nitrate precursors into hydroxides, and a pyrolysis step (at $300{ }^{\circ} \mathrm{C}$ ) for the transformation of the hydroxides into oxides $\left(\mathrm{Fe}_{2} \mathrm{O}_{3}\right.$ and/or $\left.\mathrm{Fe}_{3} \mathrm{O}_{4}\right)$ and the release of some porosity (see Scheme 1). ${ }^{38,49}$ In order to investigate the effects of the iron oxide content on the arsenic adsorption efficiency, four composites with varying iron oxide content were synthesized by tuning the feed ratio of S-CNS and iron nitrate (see Experimental section). Fig. 4 shows the TGA curves of the resulting composites in an air atmosphere, along. with those of CNS, A-CNS, and S-CNS for comparison. Among the three carbon materials (CNS, A-CNS, and S-CNS), CNS shows the best thermal stability in air given its highest $\mathrm{C}$ content. It starts to show weight loss at around $450{ }^{\circ} \mathrm{C}$ and has the complete weight loss at around $600{ }^{\circ} \mathrm{C}$ with the peak weight loss at $587^{\circ} \mathrm{C}$. A-CNS starts to lose weight at $c a .300{ }^{\circ} \mathrm{C}$ and have complete weight loss at $500{ }^{\circ} \mathrm{C}$ with peak weigh loss temperature of $470{ }^{\circ} \mathrm{C}$, due to its enhanced porosity and surface area for contact with air. S-CNS instead starts to lose weight at as early as $130{ }^{\circ} \mathrm{C}$ and the weight loss covers a broad temperature range of 130 to $600{ }^{\circ} \mathrm{C}$, with the peak temperature of $560{ }^{\circ} \mathrm{C}$. The weight loss at the low temperature region is attributed to the loss of the labile oxygen-containing functionalities upon heating.

The $\mathrm{FeO}_{x}$-CNS nanocomposites all show weight loss within the temperature range of $220-480^{\circ} \mathrm{C}$, which should correspond primarily to the combustion of the carbon matrix. The peak maximum temperature is within the range of $360-400^{\circ} \mathrm{C}$, which 


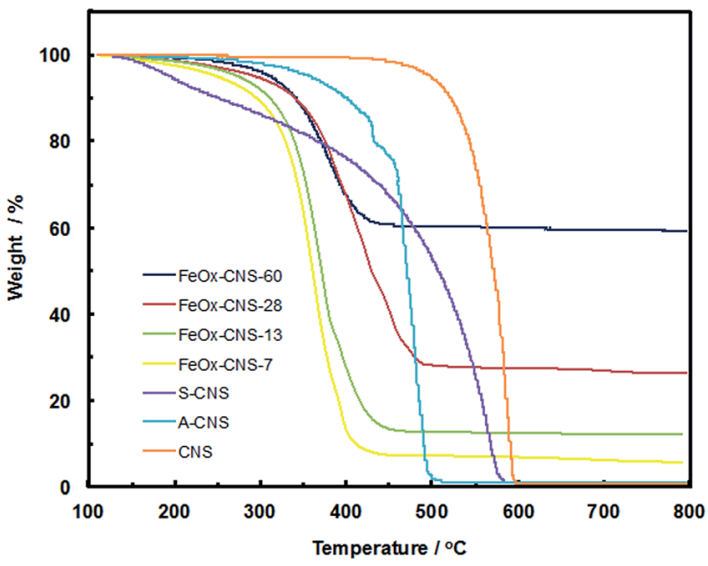

Fig. 4 TGA curves of CNS, A-CNS, S-CNS, and $\mathrm{FeO}_{x}-\mathrm{CNS}$ composites in air.

is significantly reduced relative to that of S-CNS. This should be ascribed to the existence of iron oxide nanoparticles on the surfaces of the carbon matrix which act as catalysts for the carbon combustion since their exothermic oxidation takes place at lower temperatures. ${ }^{50}$ Different from the complete weight loss observed in the carbon samples, the composites show different residual char yield at $500{ }^{\circ} \mathrm{C}(7,13,28$, and $60 \mathrm{wt} \%$, respectively), corresponding to the content of iron oxide within the nanocomposites. Consequently, these composites are termed as $\mathrm{FeO}_{x}$-CNS-\#, with the number (\#) representing the mass percentage of iron oxide in the composites.

The composites were characterized with XPS and FTIR for their spectroscopic properties. The XPS spectra of $\mathrm{FeO}_{x}-\mathrm{CNS}-28$ as the representative one are shown in Fig. S3 and S4 in ESI. $\uparrow$ Relative to S-CNS, $\mathrm{FeO}_{x}-\mathrm{CNS}-28$ has slightly reduced $\mathrm{C}$ and $\mathrm{O}$ content of 71.6 and 18.0 atom\%, respectively, but with the significant presence of $\mathrm{Fe}$ at 4.0 atom\%, confirming the incorporation of iron oxide. From its $\mathrm{Fe}_{2 \mathrm{p}}$ spectrum and the deconvoluted peaks (Fig. S3(c) in ESI $\dagger$ ), both $\mathrm{Fe}^{3+}$ and $\mathrm{Fe}^{2+}$ species are present in the composite. In particular, the presence of $\mathrm{Fe}^{3+}$ species is confirmed by the $\mathrm{Fe}_{2 \mathrm{p}_{3 / 2}}$ peak at $712.58 \mathrm{eV}$ and the associated satellite peak at $719.08 \mathrm{eV}, \mathrm{Fe}_{2 \mathrm{p}_{1 / 2}}$ peak at $726.18 \mathrm{eV}$ and the satellite peak at $732.68 \mathrm{eV}$; the $\mathrm{Fe}^{2+}$ species is confirmed by the $\mathrm{Fe}_{2 \mathrm{p}_{3 / 2}}$ peak at $710.68 \mathrm{eV}$ and the satellite peak at $715.78 \mathrm{eV}, \mathrm{Fe}_{2 \mathrm{p}_{1 / 2}}$ peak at $724.28 \mathrm{eV}$ and the satellite peak at $729.38 \mathrm{eV}$ (see Fig. S3(c) in ESI $\dagger$ ). ${ }^{51,52}$ The formation of $\mathrm{Fe}^{2+}$ can be attributed to the reducing ability of carbon matrix during the pyrolysis treatment in the synthesis. ${ }^{17}$ In particular, the $\mathrm{Fe}^{3+} /$ $\mathrm{Fe}^{2+}$ ratio according to the $\mathrm{Fe}_{2 \mathrm{P}_{3 / 2}}$ peaks is estimated to be $1.57: 1$, which is close to the ratio of $2: 1$ for $\mathrm{Fe}_{3} \mathrm{O}_{4} \cdot{ }^{36}$ This indicates that the iron oxide present in the composite is primarily $\mathrm{Fe}_{3} \mathrm{O}_{4}$ and the presence of $\gamma-\mathrm{Fe}_{2} \mathrm{O}_{3}$ should be minor. The $\mathrm{O}_{1 \mathrm{~s}}$ spectrum (Fig. $\mathrm{S} 4(\mathrm{a})$ in ESI $\dagger$ ) can be well fitted to three peaks at 530.3, 531.6, and $533.6 \mathrm{eV}$, which are attributed to the binding energies of oxygen atoms in the $\mathrm{O}-\mathrm{Fe}$, carboxyl $\mathrm{O}=\mathrm{C}$, and hydroxyl $\mathrm{O}-\mathrm{H}$ bonds, respectively. ${ }^{53}$ The binding energy of $\mathrm{C}_{1 \mathrm{~s}}$ can be found at 284.8, 286.1, 287.7, and $288.8 \mathrm{eV}$ (Fig. S4(b) in $\mathrm{ESI} \dagger)$, in agreement with the binding energy values of $\mathrm{C}-\mathrm{C}, \mathrm{C}-$ $\mathrm{O}, \mathrm{C}=\mathrm{O}$ and $\mathrm{O}-\mathrm{C}=\mathrm{O}$ reported in the literature. ${ }^{54}$
FTIR spectra of $\mathrm{FeO}_{x}-\mathrm{CNS}-13, \mathrm{FeO}_{x}-\mathrm{CNS}-28$, and $\mathrm{FeO}_{x}-\mathrm{CNS}-$ 60 are included in Fig. 3. The basic bands attributed to the vibrations of aromatic carbon rings, carbonyl and ketone units are still observed, indicating that the carbon matrix retains the basic carbon structure and the main active groups of the parent S-CNS. The incorporation of iron oxide in the nanocomposites can be confirmed with a new broad band in the low frequency region (750-400 $\mathrm{cm}^{-1}$ ) with the peak intensity at $526 \mathrm{~cm}^{-1}$ in $\mathrm{FeO}_{x}-\mathrm{CNS}-28$ and $\mathrm{FeO}_{x}-\mathrm{CNS}-60$ of significantly high iron oxide contents, which corresponds to the $\mathrm{Fe}-\mathrm{O}$ vibration in $\mathrm{Fe}_{3} \mathrm{O}_{4}$ and $\gamma-\mathrm{Fe}_{2} \mathrm{O}_{3}{ }^{39}$

Fig. 5 shows the XRD spectra of two representative composites, $\mathrm{FeO}_{x}-\mathrm{CNS}-13$ and $\mathrm{FeO}_{x}-\mathrm{CNS}-60$, along with those of A-CNS and S-CNS. In the spectra of all samples, two weak but broad peaks (indicated by arrows), attributed to the (002) and (100) peaks of graphitic structures, are found at around 24 and $43^{\circ}$, respectively. ${ }^{55}$ The weak and broad nature of the peaks suggests a low degree of graphitization with a low content of parallel single layers in these carbon materials, which is typical of amorphous carbon materials. Apart from the diffraction peaks of the carbon matrix, distinct diffractions arising from $\mathrm{Fe}_{3} \mathrm{O}_{4}$ and/or $\gamma-\mathrm{Fe}_{2} \mathrm{O}_{3}$ crystals (indicated by solid squares and open circles, respectively) can be clearly seen in the spectrum of $\mathrm{FeO}_{x}-\mathrm{CNS}-60$ having the highest iron oxide content. These peaks can be indexed to the diffractions of $\mathrm{Fe}_{3} \mathrm{O}_{4}$ (JCPDS card no. 88-0315) and $\gamma-\mathrm{Fe}_{2} \mathrm{O}_{3}$ (JCPDS card no. 39-1346), which are indistinguishable. ${ }^{17}$ Herein, given the minor presence of $\gamma$ $\mathrm{Fe}_{2} \mathrm{O}_{3}$ in the composite according to the XPS results above, these diffraction peaks should thus result predominantly from $\mathrm{Fe}_{3} \mathrm{O}_{4}$. The average crystallite size $(L)$ is evaluated from the full width at half maximum of the (311) peak at $2 \theta=35.5^{\circ}$ according to the Scherrer equation:

$$
L=K \lambda / \beta \cos \theta
$$

where $K$ is the shape factor usually assigned as $0.9, \lambda$ is the wavelength used $(1.54 \AA)$, and $\beta$ is the full width at half-

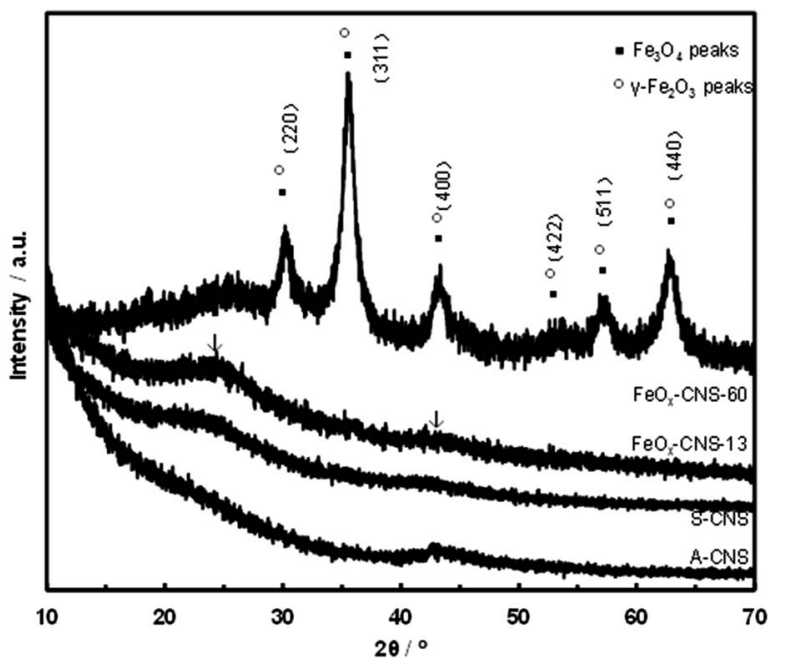

Fig. 5 XRD patterns of A-CNS, S-CNS, $\mathrm{FeO}_{x}-\mathrm{CNS}-13$, and $\mathrm{FeO}_{x}-$ CNS-60. 
maximum (in rad) of the diffraction peak. The resulting $L$ is about $8 \mathrm{~nm}$. This size is much smaller than the size of large iron oxide aggregates seen under DF-STEM (shown below), indicating the polycrystalline nature of the aggregates. In the spectrum of $\mathrm{FeO}_{x}-\mathrm{CNS}-13$, characteristic peaks resulting from the iron oxide are not seen due to the low iron oxide content.

TEM characterization of two representative composites, $\mathrm{FeO}_{x}-\mathrm{CNS}-13$ and $\mathrm{FeO}_{x}-\mathrm{CNS}-60$, was conducted, with typical TEM images shown in Fig. 6 and S5 in ESI, $\dagger$ respectively. In $\mathrm{FeO}_{x}-\mathrm{CNS}-13$, some nanospheres can still be observed (see Fig. 6(a)) though not as well defined as those in S-CNS. The presence of iron oxide nanoparticles in the composite can be confirmed from the high-resolution TEM (HRTEM) image shown in Fig. 6(b). In particular, the inset in Fig. 6(b) clearly demonstrates the crystalline lattices with a $d$-spacing of $\sim 2.5 \AA$, which matches well the $d_{311}$ of $\mathrm{Fe}_{3} \mathrm{O}_{4} / \gamma-\mathrm{Fe}_{2} \mathrm{O}_{3} \cdot{ }^{38}$ Fig. 6(c) shows a dark-field scanning transmission electron microscopy (DF STEM) image of $\mathrm{FeO}_{x}-\mathrm{CNS}$-13. In DF-STEM images, heavy atoms such as Fe appear brighter compared to the light atoms (e.g., C or O). As shown in Fig. 6(c), uniformly distributed bright spots with sizes of around 3-4 nm, corresponding to the iron oxide nanoparticles, can be found in the dark domain of $\mathrm{FeO}_{x}-\mathrm{CNS}$ 13. The uniform dispersion of iron oxide nanoparticles in the carbon matrix is further confirmed by high-resolution elemental mapping for $\mathrm{C}$, O, and Fe (Fig. 6(d)-(f), respectively), where the $\mathrm{C}$, $\mathrm{O}$, and $\mathrm{Fe}$ elements are quite uniformly distributed and faithfully correlated with the domain. Due to the significantly higher iron oxide content, the carbon nanosphere morphology is no longer observable in $\mathrm{FeO}_{x}-\mathrm{CNS}-60$ (see Fig. S5(a) and (b) in ESI $\dagger$ ) and its DF STEM image (Fig. S5(c) in ESI $\dagger$ ) reveals much denser distribution of large iron oxide

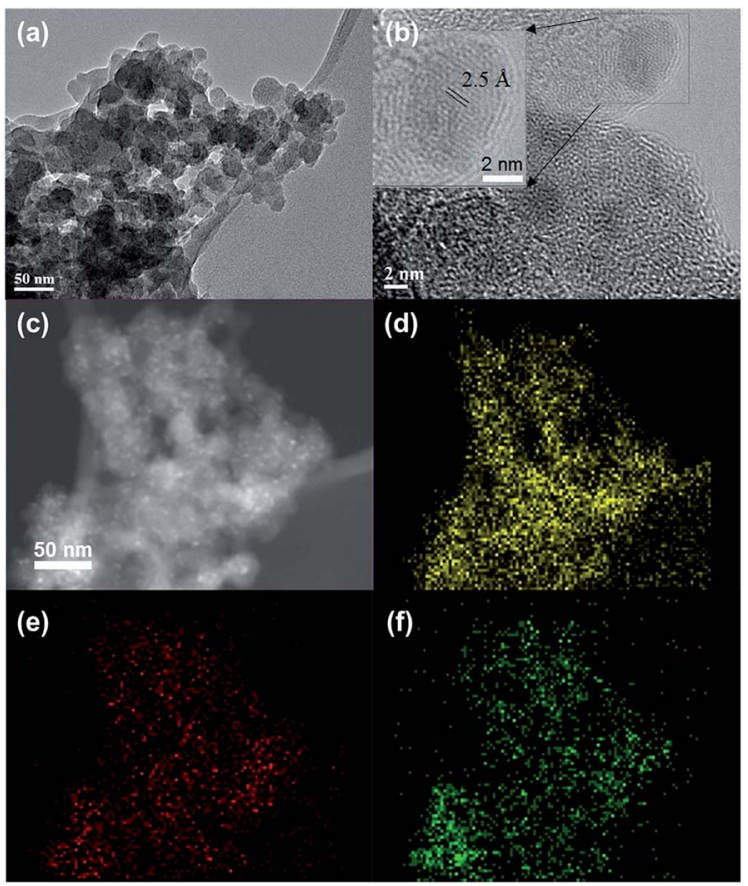

Fig. 6 TEM (a), HRTEM images (b), DF-STEM image (c) and the corresponding $\mathrm{C}$ (d) $\mathrm{O}$ (e) and $\mathrm{Fe}(\mathrm{f})$ elemental maps of $\mathrm{FeO}_{x}-\mathrm{CNS}-13$. aggregates. Unlike the small, interspersed nanoparticles seen in $\mathrm{FeO}_{x}-\mathrm{CNS}-13$, the iron oxide in $\mathrm{FeO}_{x}-\mathrm{CNS}-60$ forms the interconnected networks within the pores of the carbon matrix. Nevertheless, overall uniform distribution of the iron oxide within the composite is still maintained in $\mathrm{FeO}_{x}-\mathrm{CNS}-60$ on the basis of the C, O, and Fe elemental maps (Fig. S5(d)-(f) in ESI $\dagger$ ).

With the increase of iron oxide content, the composites show continuously reduced $\mathrm{N}_{2}$ sorption with much lowered surface area and pore volume relative to S-CNS (see Fig. 2(b) and Table 1). While both $\mathrm{FeO}_{x}-\mathrm{CNS}-13$ and $\mathrm{FeO}_{x}-\mathrm{CNS}-28$ still show the type IV isotherm with a hysteresis loop at the high relative pressure end $\left(P / P_{0}: 0.8-1\right), \mathrm{FeO}_{x}-\mathrm{CNS}-60$ of highest iron oxide content exhibits instead a type I isotherm with no distinct hysteresis loop (i.e., minor presence of mesopores/macropores). The surface area and pore volume decrease consistently from $311 \mathrm{~m}^{2} \mathrm{~g}^{-1}$ and $0.55 \mathrm{~cm}^{3} \mathrm{~g}^{-1}$ for $\mathrm{FeO}_{x}-\mathrm{CNS}-13$ to $135 \mathrm{~m}^{2} \mathrm{~g}^{-1}$ and $0.22 \mathrm{~cm}^{3} \mathrm{~g}^{-1}$ for $\mathrm{FeO}_{x}-\mathrm{CNS}-28$, and to $123 \mathrm{~m}^{2} \mathrm{~g}^{-1}$ and $0.03 \mathrm{~cm}^{3}$ $\mathrm{g}^{-1}$ for $\mathrm{FeO}_{x}-\mathrm{CNS}-60$. These results indicate the significant pore filling and blockage upon the encapsulation of iron oxide within the carbon matrix, which become increasingly severe with the increase of the iron oxide content. In particular, such filling and blockage are reasoned to be more prevalent within mesopores/ macropores since the percentages of mesopore/macropore surface and volume decrease while those for micropores increase (see Table 1) upon the encapsulation of iron oxide relative to S-CNS.

\section{Arsenic adsorption with $\mathrm{FeO}_{\boldsymbol{x}}-\mathrm{CNS}$ composites}

A systematic investigation on the performance of the set of $\mathrm{FeO}_{x}-\mathrm{CNS}$ composite adsorbents in arsenic adsorption was undertaken. Batch equilibrium adsorption of both As(III) and As(v) was carried out at the initial arsenic concentrations of 50$2000 \mathrm{mg} \mathrm{L}^{-1}$ for $\mathrm{As}(\mathrm{III})\left(\right.$ at $\mathrm{pH}=8$ ) and $50-1000 \mathrm{mg} \mathrm{L}^{-1}$ for As(v) (at $\mathrm{pH}=3$ ). The specific $\mathrm{pH}$ values are chosen herein since the composite adsorbents show optimum arsenic adsorption at the conditions according to the study on the effect of $\mathrm{pH}$ below. Due to the relatively low iron oxide contents in $\mathrm{FeO}_{x}-\mathrm{CNS}-7, \mathrm{FeO}_{x}-$ CNS-13, and $\mathrm{FeO}_{x}$-CNS-28, magnetic separation of the composites from the solution following arsenic adsorption was inefficient. As such, the separation was made by filtration. On the contrary, magnetic separation of $\mathrm{FeO}_{x}-\mathrm{CNS}-60$ was spontaneous given its high iron oxide content.

Fig. 7 shows the adsorption isotherms of the various composites at $23{ }^{\circ} \mathrm{C}$, as well as those of A-CNS and S-CNS as control ones. The two control carbon nanosphere samples without containing iron oxide show similar isotherms for both As(III) and As(v), with S-CNS having slightly raised isotherms relative to A-CNS possibly due to its more hydrophilic surface. For the composites, the content of iron oxide shows a dramatic effect on their arsenic adsorption. Relative to the carbon samples, the incorporation of iron oxide at 7 and $13 \mathrm{wt} \%$ in $\mathrm{FeO}_{x}-\mathrm{CNS}-7$ and $\mathrm{FeO}_{x}-\mathrm{CNS}-13$ leads to significantly improved arsenic adsorption with increasingly raised isotherms for both $\operatorname{As}(\mathrm{III})$ and $\operatorname{As}(\mathrm{v})$. However, the further increase of iron oxide content to higher values of 28 and $60 \mathrm{wt} \%$ instead lowers the isotherms, which become close to those of the two control samples. 

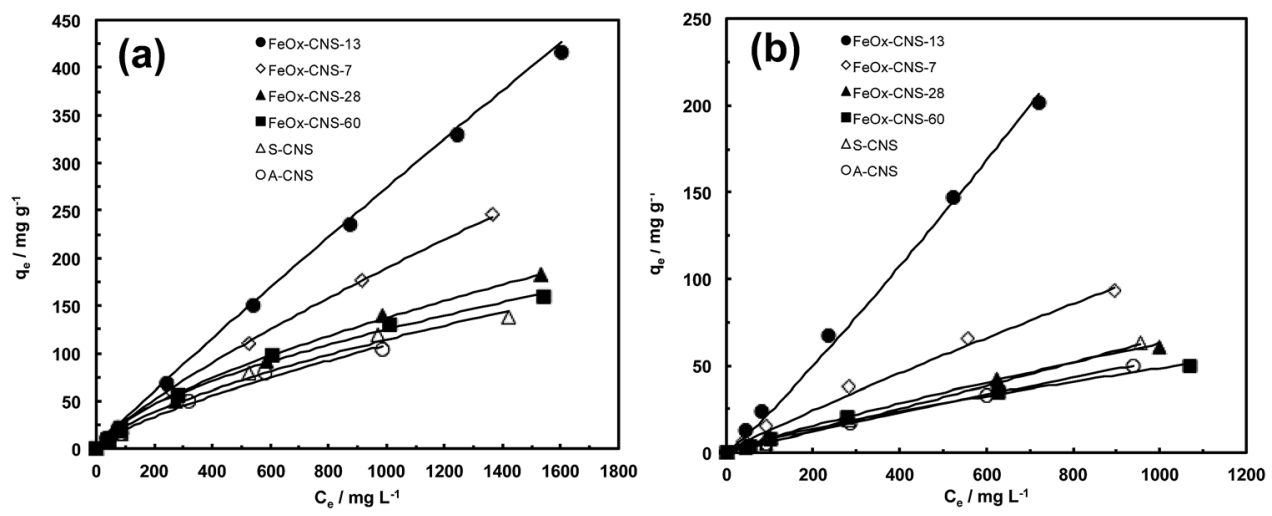

Fig. 7 (a) As(III) adsorption isotherms (at $\mathrm{pH}=8$ ) and (b) $\mathrm{As}\left(\mathrm{v}\right.$ ) adsorption isotherms (at $\mathrm{pH}=3$ ) of $\mathrm{A}-\mathrm{CNS}, \mathrm{S}-\mathrm{CNS}_{\text {, and FeO }}-\mathrm{CNS}$ composites. The adsorption isotherms are fitted the Freundlich adsorption model (solid line).

All the isotherms have been found to follow Freundlich adsorption model (eqn (1)) with $R^{2}$ values close to 1 (see Table S1 in ESI $\dagger$ ). The Langmuir model instead does not give good fitting with low $R^{2}$ values yielded. The adsorption capacity data $\left(q_{\max }\right)$, taken from the last point in each isotherm (i.e., highest adsorption uptake in each isotherm), are summarized in Table S2 in ESI. $\uparrow$ With any given adsorbent herein, we find that the adsorption capacity for $\mathrm{As}(\mathrm{III})$ is always higher than that for $\operatorname{As}(\mathrm{v})$. This is beneficial and desirable because of the prevalence of more toxic As(III) in groundwater and wastewater. ${ }^{1}$ The two carbon nanosphere samples, A-CNS and S-CNS, show $q_{\max }$ of 104 and $138 \mathrm{mg} \mathrm{g}^{-1}$, respectively, for As(III) and 50 and $63 \mathrm{mg}$ $\mathrm{g}^{-1}$, respectively, for As(v). These $q_{\max }$ data are significantly higher than the values reported for various activated carbons within the similar range of initial arsenic concentration, ${ }^{56}$ possibly due to the much higher accessible surface area of the carbon nanosphere samples as a result of their hierarchical pore structures.

The two composites having relatively low iron oxide contents, $\mathrm{FeO}_{x}-\mathrm{CNS}-7$ and $\mathrm{FeO}_{x}-\mathrm{CNS}-13$, show dramatically enhanced adsorption capacity, 246 and $416 \mathrm{mg} \mathrm{g}^{-1}$, respectively, for $\mathrm{As}(\mathrm{III})$, and 93 and $201 \mathrm{mg} \mathrm{g}^{-1}$, respectively, for As(v). In our best knowledge, the As(III) adsorption capacity of $416 \mathrm{mg}$ $\mathrm{g}^{-1}$ for $\mathrm{FeO}_{x}-\mathrm{CNS}-13$ is by far the highest among the various iron oxide-based adsorbents (see Table 2). It is even higher than the value of $320 \mathrm{mg} \mathrm{g}^{-1}$ for a high-performance $\gamma-\mathrm{Fe}_{2} \mathrm{O}_{3}$-macroporous silica composite adsorbent reported by $\mathrm{Yu}$ et al. ${ }^{41}$ Meanwhile, the $\mathrm{As}(\mathrm{v})$ adsorption capacity of $201 \mathrm{mg} \mathrm{g}^{-1}$ for $\mathrm{FeO}_{x}$-CNS-13 is also comparable to some best values (up to $248 \mathrm{mg} \mathrm{g}^{-1}$; see Table 2) reported..$^{41}$ These capacity data are remarkable given the encapsulation of iron oxide at such low contents. Clearly, the small non-aggregated iron oxide nanoparticles interspersed uniformly on the porous carbon nanosphere matrix contribute to the dramatic enhancement in the adsorption capacity since their surface is more active than the carbon surface for arsenic adsorption. Increasing the iron oxide content within this range $(<c a .13 \mathrm{wt} \%)$ is thus beneficial for enhanced capacity.

Relative to $\mathrm{FeO}_{x}$-CNS-13, the other two composites, $\mathrm{FeO}_{x^{-}}$ CNS-28 and $\mathrm{FeO}_{x}-\mathrm{CNS}-60$, instead show much deteriorated adsorption capacity data (182 and $160 \mathrm{mg} \mathrm{g}^{-1}$, respectively, for $\operatorname{As}(\mathrm{III}) ; 61$ and $50 \mathrm{mg} \mathrm{g}^{-1}$, respectively, for $\left.\mathrm{As}(\mathrm{V})\right)$ despite the higher iron oxide contents. Within this range of iron oxide content ( $c a .28-60 \mathrm{wt} \%$ ), the increase in iron oxide content is detrimental to arsenic adsorption. This should result from the formation of large iron oxide aggregates, which leads to filled/ blocked pores and reduced active surface area for effective arsenic adsorption. Clearly, $13 \mathrm{wt} \%$ is approximately the optimum iron oxide content for this range of composite adsorbents. A similar trend of change in arsenic adsorption capacity has been noted in iron-impregnated granular activated carbon adsorbents, where the adsorption capacity increases with the iron content up to $6 \%$ and then decreases with further increase in the content. ${ }^{24}$

The adsorption kinetics of $\mathrm{FeO}_{x}$-CNS-13 was monitored at the initial arsenic concentration of $950 \mathrm{mg} \mathrm{L}^{-1}$ for As(III) (at pH

Table 2 Comparison of arsenic adsorption capacity data of representative iron oxide-based adsorbents

\begin{tabular}{|c|c|c|c|}
\hline \multirow[b]{2}{*}{ Iron oxide-based adsorbents } & \multicolumn{2}{|c|}{$\begin{array}{l}\text { Adsorption } \\
\text { capacity } \\
\left(\mathrm{mg} \mathrm{g}^{-1}\right)\end{array}$} & \multirow[b]{2}{*}{ Reference } \\
\hline & $\operatorname{As}(\mathrm{III})$ & $\operatorname{As}(v)$ & \\
\hline $\mathrm{Fe}_{3} \mathrm{O}_{4}$ nanoparticles $(12 \mathrm{~nm})$ & 160 & 180 & 13 \\
\hline $\mathrm{Fe}_{2} \mathrm{O}_{3} \mathrm{CAHNs}$ & & 137.5 & 16 \\
\hline Flowerlike $\alpha-\mathrm{Fe}_{2} \mathrm{O}_{3}$ & & 51 & 15 \\
\hline Hollow nestlike $\alpha-\mathrm{Fe}_{2} \mathrm{O}_{3}$ & 58.6 & 75.3 & 21 \\
\hline$\gamma-\mathrm{Fe}_{2} \mathrm{O}_{3}$ nanochains & & 162 & 22 \\
\hline Bimetal iron(III)-titanium(Iv) oxide & 85 & 14.3 & 8 \\
\hline $\mathrm{Fe}-\mathrm{Cu}$ binary oxide & 122.3 & 82.7 & 57 \\
\hline Hollow Fe-Ce alkoxides & 266 & 206 & 58 \\
\hline $\mathrm{Fe}_{3} \mathrm{O}_{4}-\mathrm{RGO}$ & 13.1 & 5.83 & 25 \\
\hline $\mathrm{Fe}_{2} \mathrm{O}_{3}$-graphene nanoplatelet & 11.34 & & 29 \\
\hline $\mathrm{Fe}_{2} \mathrm{O}_{3}$-cellulose & 23.16 & 32.11 & 37 \\
\hline $\mathrm{Fe}_{2} \mathrm{O}_{3}$-ordered mesoporous carbon & 29.4 & 17.9 & 38 \\
\hline Ce-Fe oxide@carbon nanotube & 28.74 & 30.96 & 40 \\
\hline $\mathrm{Fe}_{2} \mathrm{O}_{3}$-carbon aerogel & & 216 & 59 \\
\hline $\mathrm{Fe}_{2} \mathrm{O}_{3}$-diatomite & 60.65 & 81.16 & 60 \\
\hline $\mathrm{Fe}_{2} \mathrm{O}_{3}-$ macroporous silica & 320 & 248 & 41 \\
\hline $\mathrm{FeO}_{x}-\mathrm{CNS}-13$ & 416 & 201 & This study \\
\hline
\end{tabular}


$=8$ ) and $800 \mathrm{mg} \mathrm{L}^{-1}$ for $\mathrm{As}(\mathrm{v})($ at $\mathrm{pH}=3$ ). Fig. 8 shows the kinetic curves. For both curves, the adsorption can be divided into two stages, a rapid uptake within the first $30 \mathrm{~min}$ of contact and a slow uptake thereafter until equilibrium is reached. In particular, the majority of the arsenic uptake, 62 and $73 \%$ for As(III) and As(v), respectively, occurs within the first $30 \mathrm{~min}$, indicating the very fast adsorption rate. The adsorption kinetics can be perfectly fitted with a pseudo-second-order model (eqn (2) or (3)) with the rate constant $k_{2}$ of 0.000315 and $0.000504 \mathrm{~g}$ $\mathrm{mg}^{-1} \mathrm{~min}^{-1}$ for As(III) and As(v), respectively. The $k_{2}$ values are high, in particular for As(III), when compared to other superior adsorbents reported in the literature. For example, the highperformance $\gamma-\mathrm{Fe}_{2} \mathrm{O}_{3}$-macroporous silica composite adsorbent reported by $\mathrm{Yu}$ et al. has the $k_{2}$ values of 0.00015 and $0.0014 \mathrm{~g} \mathrm{mg}^{-1} \mathrm{~min}^{-1}$ for As(III) and As(v), respectively, under similar conditions. ${ }^{41}$ These kinetic results demonstrate that, within the concentration ranges, the rapid removal of the arsenic species from wastewater can be achieved with $\mathrm{FeO}_{x}-$ CNS-13.

It is expected that the $\mathrm{pH}$ of the aqueous medium should have a crucial influence on arsenic removal by the composite adsorbents, because it greatly affects the surface charge of the composites and arsenic species distribution. ${ }^{\mathbf{1 - 4}}$ Thus, the adsorption of arsenic with $\mathrm{FeO}_{x}-\mathrm{CNS}-13$ as a function of $\mathrm{pH}$ in a broad range has been investigated. Fig. 9 plots $q_{\mathrm{e}}$ as a function of $\mathrm{pH}$ (within 2-10), which was undertaken at the initial As(III) and $\mathrm{As}(\mathrm{v})$ concentration of $1000 \mathrm{mg} \mathrm{L}^{-1}$ and the contact time of $24 \mathrm{~h}$. Clearly, arsenic adsorption with $\mathrm{FeO}_{x}-\mathrm{CNS}-13$ is strongly $\mathrm{pH}$-dependent. With the increase of $\mathrm{pH}$ from 2 to 10, the $\mathrm{As}(\mathrm{v})$ uptake capacity remains nearly constant at $197-200 \mathrm{mg} \mathrm{g}^{-1}$ in the range of 2-4, followed by the continuous drop to $150 \mathrm{mg} \mathrm{g}^{-1}$ at $\mathrm{pH}=10$. The As(III) uptake shows an opposite trend. The maximum As(III) uptake $\left(230 \mathrm{mg} \mathrm{g}^{-1}\right)$ is found at $\mathrm{pH}=8$. Both increasing and decreasing the $\mathrm{pH}$ value lead to the reduction in adsorption capacity.

Though with minor variations in the optimum $\mathrm{pH}$ values for arsenic adsorption, similar trends of change for the $\mathrm{pH}$ effects have commonly been observed with various iron oxide-based adsorbents and can be explained by the changes in surface charge of the adsorbents and the arsenic

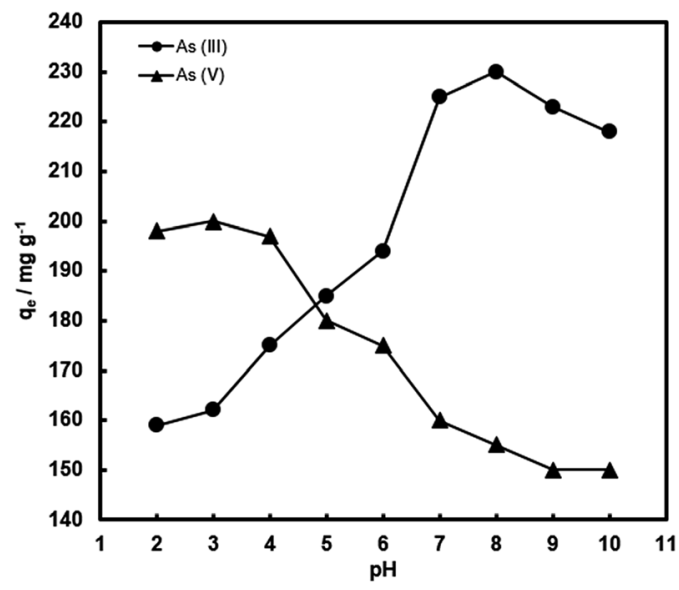

Fig. 9 Arsenic uptake of $\mathrm{FeO}_{x}-\mathrm{CNS}-13$ as a function of $\mathrm{pH}$. The initial arsenic concentration is $1000 \mathrm{mg} \mathrm{L}^{-1}$.

speciation. ${ }^{9-11,14,23-26,28,34,37,40,41}$ The point of zero charge $\left(\mathrm{pH}_{\mathrm{PZC}}\right)$ of $\mathrm{FeO}_{x}-\mathrm{CNS}-13$ is measured to be $\approx 2.8$ (Fig. S6(a) in ESI $\dagger$ ). The surface of $\mathrm{FeO}_{x}-\mathrm{CNS}-13$ is positively charged at $\mathrm{pH}<\mathrm{pH}_{\mathrm{PZC}}$, and in the $\mathrm{pH}$ range of $2-2.8$, the predominant species of $\mathrm{As}(\mathrm{v})$ is $\mathrm{H}_{2} \mathrm{AsO}_{4}{ }^{-}$with negative charge. ${ }^{2}$ The electrostatic interaction between positively charged $\mathrm{FeO}_{x}-\mathrm{CNS}-13$ and negatively charged $\mathrm{As}(\mathrm{v})$ species results in the enhanced adsorption within this $\mathrm{pH}$ range. The deprotonation of surface hydroxyl groups occurs with the increase of $\mathrm{pH}$, leading to a negatively charged surface for $\mathrm{FeO}_{x}-\mathrm{CNS}-13$ after $\mathrm{pH}$ of 2.8, and the predominant species of $\mathrm{As}(\mathrm{v})$ is $\mathrm{H}_{2} \mathrm{AsO}_{4}{ }^{-}$from $\mathrm{pH}$ 3-6.5, and $\mathrm{HAsO}_{4}{ }^{2-}$ from after $\mathrm{pH}$ of 6.5 , both with negative charge. It thus results in the reduced $\operatorname{As}(\mathrm{v})$ adsorption uptake. However, the adsorption of As(III) on $\mathrm{FeO}_{x}-\mathrm{CNS}-13$ is different. The optimum $\mathrm{pH}$ for As(III) adsorption is 8 . When the $\mathrm{pH}$ value is below 8 , the arsenic removal efficiency significantly increases with the increase of $\mathrm{pH}$, but decreases when $\mathrm{pH}$ is above 8 . The solubilization and leaching of $\mathrm{Fe}$ species into the acidic solution at $\mathrm{pH} 2-6$ (Fig. S6(b) in ESI $\dagger$ ) is the primary reason for the reduced As(III) adsorption capacity with the decrease of $\mathrm{pH}$ in this range. ${ }^{25}$ At $\mathrm{pH}<9.2$, As(III) exists mainly as $\mathrm{H}_{3} \mathrm{AsO}_{3},{ }^{2}$ indicating $\mathrm{As}(\mathrm{III})$ is adsorbed on $\mathrm{FeO}_{x}-\mathrm{CNS}-13$ through a surface complexation
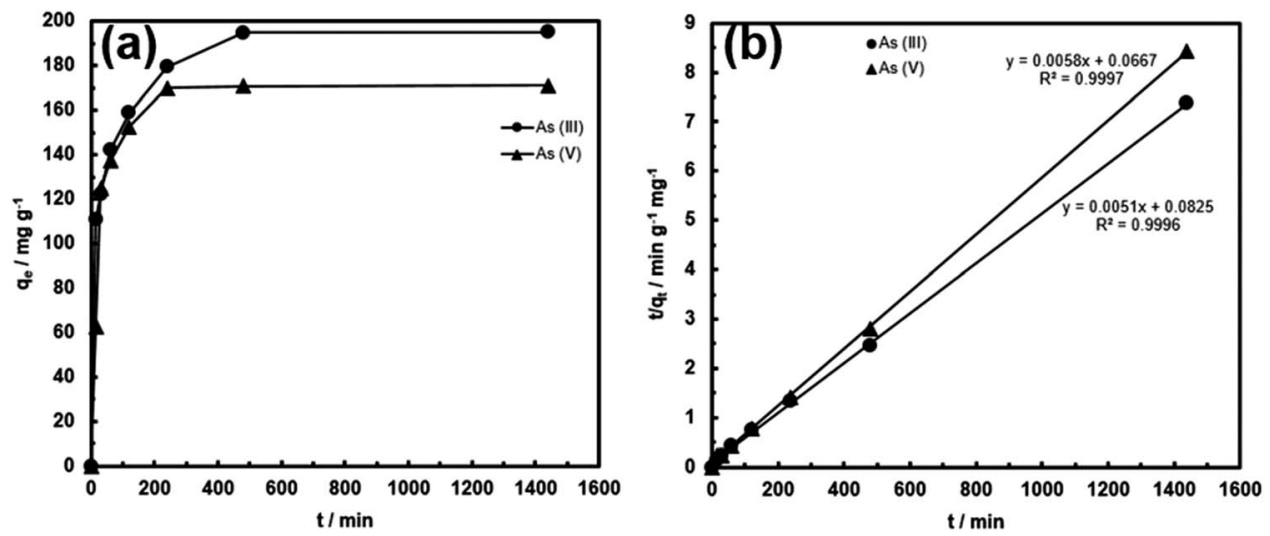

Fig. 8 (a) As(III) and As(v) adsorption kinetic curves of $\mathrm{FeO}_{x}-\mathrm{CNS}-13$; (b) fitting of the kinetic data with the pseudo-second-order model. 
mechanism. ${ }^{25}$ The removal efficiency drops at $\mathrm{pH}>9$ due to the ionization of $\mathrm{H}_{3} \mathrm{AsO}_{3}$ to $\mathrm{H}_{2} \mathrm{AsO}_{3}{ }^{-}$with negative charge, which results in the occurrence of more competition between arsenite and $\mathrm{OH}^{-}$anions. Moreover, the increasing coulombic repulsion between As(III) species and the negative surface of $\mathrm{FeO}_{x}-\mathrm{CNS}-13$ may be another important reason for the decrease in As(III) uptake when $\mathrm{pH}>9$.

\section{Conclusions}

A set of $\mathrm{FeO}_{x}-\mathrm{CNS}$ nanocomposite adsorbents has been successfully synthesized by encapsulating iron oxide at different content (7-60 wt\%) into a high-surface-area high-pore-volume carbon nanosphere matrix with hierarchical pore structure, SCNS. Detailed characterizations of the nanocomposites have been undertaken. TEM results reveal the overall uniform distribution of the crystalline iron oxide within the nanocomposites. In $\mathrm{FeO}_{x}$-CNS-13, small iron oxide nanoparticles with sizes of 3-4 $\mathrm{nm}$ are interspersed uniformly on the carbon nanosphere matrix, with the retention of the hierarchical pore structures. On the contrary, aggregates of iron oxide are observed in $\mathrm{FeO}_{x}-\mathrm{CNS}-60$ with severe pore filling and blockage. XPS and XRD results indicate that the iron oxide species is primarily crystalline $\mathrm{Fe}_{3} \mathrm{O}_{4}$. The adsorption of both $\mathrm{As}(\mathrm{III})$ and $\mathrm{As}(\mathrm{v})$ has been investigated with the nanocomposites. Best adsorption performance is achieved with $\mathrm{FeO}_{x}-\mathrm{CNS}-13$ having the optimum iron oxide content, with superior adsorption capacity of 416 and $201 \mathrm{mg} \mathrm{g}^{-1}$ for As(III) and As(v), respectively, which are highest or among the highest reported thus far in the literature. Both reducing and increasing the iron oxide content lead to the reduced arsenic adsorption. Meanwhile, from the adsorption kinetics, $\mathrm{FeO}_{x}-\mathrm{CNS}-13$ is also featured with high adsorption rate. The results confirm the high potential of $\mathrm{FeO}_{x}-$ CNS-13 as superior adsorbents for arsenic removal from industrial wastewater streams.

\section{Conflicts of interest}

There are no conflicts of interest to declare.

\section{Acknowledgements}

The financial support from the Natural Science and Engineering Research Council (NSERC) of Canada (Grant \#: EGP 491823-15 and EGP2 503876-16) and Goldcorp Inc. is greatly appreciated. HS also thanks Laurentian University for awarding incentive graduate scholarships.

\section{References}

1 W. R. Cullen and K. J. Reimer, Chem. Rev., 1989, 89, 713-764. 2 P. L. Smedley and D. G. Kinniburgh, Appl. Geochem., 2002, 17, 517-568.

3 D. Mohan and C. U. Pittman Jr, J. Hazard. Mater., 2007, 142, 1-53.

4 T. S. Y. Choong, T. G. Chuah, Y. Robiah, F. L. G. Koay and I. Azni, Desalination, 2007, 217, 139-166.
5 Z. Cheng, F. Fu, D. D. Dionysiou and B. Tang, Water Res., 2016, 96, 22-31.

6 M. Kobya, E. Demirbas and F. Ulu, J. Environ. Chem. Eng., 2016, 4, 1484-1494.

7 S. C. N. Tang and I. M. C. Lo, Water Res., 2013, 47, 2613-2632.

8 M. L. Pierce and C. B. Moore, Water Res., 1982, 16, 12471253.

9 K. P. Raven, A. Jain and R. H. Loeppert, Environ. Sci. Technol., 1998, 32, 344-349.

10 S. Dixit and J. G. Hering, Environ. Sci. Technol., 2003, 37, 4182-4189.

11 S. Luther, N. Borgfeld, J. Kim and J. G. Parsons, Microchem. J., 2012, 101, 30-36.

12 S. Yean, L. Cong, C. T. Yavuz, J. T. Mayo, W. W. Yu, A. T. Kan, V. L. Colvin and M. B. Tomson, J. Mater. Res., 2005, 20, 32553264.

13 C. T. Yavuz, J. T. Mayo, W. W. Yu, A. Prakash, J. C. Falkner, S. Yean, L. Cong, H. J. Shipley, A. Kan, M. Tomson, D. Natelson and V. L. Colvin, Science, 2006, 314, 964-967.

14 T. Tuutijärvi, J. Lu, M. Sillanpää and G. Chen, J. Hazard. Mater., 2009, 166, 1415-1420.

15 L.-S. Zhong, J.-S. Hu, H.-P. Liang, A.-M. Cao, W.-G. Song and L.-J. Wan, Adv. Mater., 2006, 18, 2426-2431.

16 F. Mou, J. Guan, Z. Xiao, Z. Sun, W. Shi and X.-A. Fan, J. Mater. Chem., 2011, 21, 5414-5421.

17 F. Mou, J. Guan, H. Ma, L. Xu and W. Shi, ACS Appl. Mater. Interfaces, 2012, 4, 3987-3993.

18 C.-Y. Cao, J. Qu, W.-S. Yan, J.-F. Zhu, Z.-Y. Wu and W.-G. Song, Langmuir, 2012, 28, 4573-4579.

19 B. Wang, H. Wu, L. Yu, R. Xu, T.-T. Lim and X. W. Lou, Adv. Mater., 2012, 24, 1111-1116.

20 T. Wang, L. Zhang, H. Wang, W. Yang, Y. Fu, W. Zhou, W. Yu, K. Xiang, Z. Su, S. Dai and L. Chai, ACS Appl. Mater. Interfaces, 2013, 5, 12449-12459.

21 Z. Wei, R. Xing, X. Zhang, S. Liu, H. Yu and P. Li, ACS Appl. Mater. Interfaces, 2013, 5, 598-604.

22 G. K. Das, C. S. Bonifacio, J. De Rojas, K. Liu, K. van Benthem and I. M. Kennedy, J. Mater. Chem. A, 2014, 2, 12974-12981.

23 M. Jang, S.-H. Min, T.-H. Kim and J. K. Park, Environ. Sci. Technol., 2006, 40, 1636-1643.

24 Z. Gu, J. Fang and B. Deng, Environ. Sci. Technol., 2005, 39, 3833-3843.

25 V. Chandra, J. Park, Y. Chun, J. W. Lee, I.-C. Hwang and K. S. Kim, ACS Nano, 2010, 4, 3979-3986.

26 K. Zhang, V. Dwivedi, C. Chi and J. Wu, J. Hazard. Mater., 2010, 182, 162-169.

27 X.-L. Wu, L. Wang, C.-L. Chen, A.-W. Xu and X.-K. Wang, J. Mater. Chem., 2011, 21, 17353-17359.

28 G. Sheng, Y. Li, X. Yang, X. Ren, S. Yang, J. Hu and X. Wang, RSC Adv., 2012, 2, 12400-12407.

29 J. Zhu, R. Sadu, S. Wei, D. H. Chen, N. Haldolaarachchige, Z. Luo, J. A. Gomes, D. P. Young and Z. Guo, ECS J. Solid State Sci. Technol., 2012, 1, M1-M5.

30 J. Zhu, S. Wei, H. Gu, S. B. Rapole, Q. Wang, Z. Luo, N. Haldolaarachchige, D. P. Young and Z. Guo, Environ. Sci. Technol., 2012, 46, 977-985. 
31 Y. Wang, Q. He, H. Qu, X. Zhang, J. Guo, J. Zhu, G. Zhao, H. A. Colorado, J. Yu, L. Sun, S. Bhana, M. A. Khan, X. Huang, D. P. Young, H. Wang, X. Wang, S. Wei and Z. Guo, J. Mater. Chem. C, 2014, 2, 9478-9488.

32 G. Gollavelli, C.-C. Chang and Y.-C. Ling, ACS Sustainable Chem. Eng., 2013, 1, 462-472.

33 B. Paul, V. Parashar and A. Mishra, Environ. Sci.: Water Res. Technol., 2015, 1, 77-83.

34 F. Yu, S. Sun, J. Ma and S. Han, Phys. Chem. Chem. Phys, 2015, 17, 4388-4397.

35 J. Ding, B. Li, Y. Liu, X. Yan, S. Zeng, X. Zhang, L. Hou, Q. Cai and J. Zhang, J. Mater. Chem. A, 2015, 3, 832-839.

36 H. Su, Z. Ye and N. Hmidi, Colloids Surf., A, 2017, 522, 161172.

37 X. Yu, S. Tong, M. Ge, J. Zuo, C. Cao and W. Song, J. Mater. Chem. A, 2013, 1, 959-965.

38 Z. Wu, W. Li, P. A. Webley and D. Zhao, Adv. Mater., 2012, 24, 485-491.

39 M. Baikousi, A. B. Bourlinos, A. Douvalis, T. Bakas, D. F. Anagnostopoulos, J. Tucek, K. Safarova, R. Zboril and M. A. Karakassides, Langmuir, 2012, 28, 3918-3930.

40 B. Chen, Z. Zhu, J. Ma, Y. Qiu and J. Chen, J. Mater. Chem. A, 2013, 1, 11355-11367.

41 J. Yang, H. Zhang, M. Yu, I. Emmanuelawati, J. Zou, Z. Yuan and C. Yu, Adv. Funct. Mater., 2014, 24, 1354-1363.

42 V. K. Tiwari, Z. Chen, F. Gao, Z. Gu, X. Sun and Z. Ye, J. Mater. Chem. A, 2017, 5, 12131-12143.

43 J. Pastor-Villegas and C. J. Durán-Valle, Carbon, 2002, 40, 397-402.

44 Z. Wu, P. Webley and D. Zhao, Langmuir, 2010, 26, 1027710286.
45 K. S. W. Sing, D. H. Everett, R. A. W. Haul, L. Moscou, R. A. Pierotti, J. Rouquerol and T. Siemieniewska, Pure Appl. Chem., 1985, 57, 603-619.

46 A. Dandekar, R. Baker and M. Vannice, Carbon, 1998, 36, 1821-1831.

47 P. Bazula, A. Lu, J. Nitz and F. Schüth, Microporous Mesoporous Mater., 2008, 108, 266-275.

48 A. Kuznetsova, D. Mawhinney, V. Naumenko, J. Yates, J. Liu and R. Smalley, Chem. Phys. Lett., 2000, 321, 292-296.

49 Z. Wu, Q. Li, D. Peng, P. Webley and D. Zhao, J. Am. Chem. Soc., 2010, 132, 12042-12050.

50 G. Ennas, G. Marongiu and A. Musinu, J. Mater. Res., 1998, 14, 1570-1578.

51 H. Kong, J. Song and J. Jang, Chem. Commun., 2010, 46, 6735-6737.

52 G. Bhargava, I. Gouzman, C. Chun, T. Ramanarayanan and S. Bernasek, Appl. Surf. Sci., 2007, 253, 4322-4329.

53 R. Netterfield, P. Martin, C. Pacey, W. Sainty, D. Mckenzie and G. Auchterlonie, J. Appl. Phys., 1989, 66, 1805-1809.

54 S. Chao, Y. Takagi, G. Lucovsky, P. Pai, R. Custer, J. Tyler and J. Keem, Appl. Surf. Sci., 1986, 26, 575-583.

55 L. Xu, J.-W. McGraw, F. Gao, M. Grundy, Z. Ye, Z. Gu and J. Shepherd, J. Phys. Chem. C, 2013, 117, 10730-10742.

56 J. Pattanayak, K. Mondal, S. Mathew and S. B. Lalvani, Carbon, 2000, 38, 589-596.

57 G. Zhang, Z. Ren, X. Zhang and J. Chen, Water Res., 2013, 47, 4022-4031.

58 B. Chen, Z. Zhu, S. Liu, J. Hong, J. Ma, Y. Qiu and J. Chen, ACS Appl. Mater. Interfaces, 2014, 6, 14016-14025.

59 Y. Lin and J. Chen, J. Colloid Interface Sci., 2014, 420, 74-79. 60 Y. Du, H. Fan, L. Wang, J. Wang, J. Wu and H. Dai, J. Mater. Chem. A, 2013, 1, 7729-7737. 